\title{
CoMFA and CoMSIA on the Neuroblocking Activity of 1-(6-Chloro-3-pyridylmethyl)-2-nitroiminoimidazolidine Analogues
}

\author{
Nack-Do Sung," Seok-Chan Jang, and Kyoung-Seop Choi \\ Division of Applied Biology \& Chemistry, College of Agriculthre and Life Sciences, Chungnam National University, \\ Daejeon 305-764, Korea."E-mail:ndsung@cmuackr \\ Received Jily 5, 2006
}

\begin{abstract}
3D-QS $\Lambda$ Rs on the neuroblocking activities by 1-(6-chloro-3-pyridylmethyl)-2-nitroiminoimidazolidine analogues as agonist at the nicotinic acetylcholine receptor $(\mathrm{n} \Lambda \mathrm{ChR})$ were studied quantitatively using $\mathrm{CoMF} \Lambda$ and CoMSI $\Lambda$ methodologies. The statistical results of $\operatorname{CoMF} \Lambda\left(\Lambda 5: \mathrm{r}_{\mathrm{sw}}^{2}=0.707 \& \mathrm{r}_{\mathrm{nw}}^{2}=0.986\right)$ and CoMSI $\Lambda$ model $\left(\Lambda 3: r^{2}\right.$ w. $=0.715 \& r^{2}$ nev. $\left.=0.961\right)$ showed the best predictability and fitness for neuroblocking activity based on the cross-validated value and non-cross validated value. The steric and II-bond acceptor nature of a compound were essential for high activity. The study on 3D-QS $\Lambda$ Rs between substrate molecules and their neuroblocking activities appears to be an useful approach for designing better neuroblocking drug development.
\end{abstract}

Key Words : Imidacloprid analogues, Neuroblocking activity, CoMFA, CoMSIA analysis

\section{Introduction}

1-(6-Chloro-3-pyridylmethyl)-2-nitroiminoimidazolidine (common: Imidacloprid) ${ }^{\prime}$ analogues are a class of insecticides that acts selectively on insect neuronal nicotinic acetylcholine receptors (nAChRs) (i.e. neonicotinoid insecticide) is used widely to protect crop and control pest. ${ }^{2}$ In mammals, nAChR agonists have been shown to improve performance in a variety of memory tasks, whereas treatment with $\mathrm{nAChR}$ antagonists has been shown to impair memory functions. ${ }^{3}$ The nAChRs exist as various subtypes and are involved in a variety of functions and disorders of the central nervous system, such as Alzheimer and Parkinson diseases.

Recently, imidaclopride analogues were evaluated and investigated to study on seed treatment, ${ }^{4}$ uptake and persistence, ${ }^{5}$ soil functioning, ${ }^{6}$ an enzyme-linked immunosorbent assay (ELISA), ${ }^{7}$ specific nicotinic agonist ${ }^{8}$ and insecticidal neuroblocking, ${ }^{9}$ proboscis extension response (PER) assay, ${ }^{10}$ quantifying imidaclopride and it's metabolite, ${ }^{11}$ cytogenic and genotoxic effects ${ }^{12}$ of neonicotinoids. And also the nicotinic potency of many neonicotinoids have been characterized to examine the quantitative structureactivity relationships (QSARs). ${ }^{13}$ Studies on structure-affinity relationships (SAFIRs) of $n A C h R$ agonists have been reported ${ }^{14}$ To control the residual toxicity with half-life and design of new drug from transition-state mimic, it was reported previously that the hydrolysis of imidacloprid proceeds through the nucleophilic addition-elimination mechanism from kinetics data ${ }^{15}$

In this report, to find the necessary information for drug design, comparative molecular field anaylsis (CoMFA) ${ }^{16}$ and comparative molecular similarity indices analysis (COMSIA) ${ }^{17}$ were carried out to study three dimensional quantitative structure-activity relationships $(3 \mathrm{D}-\mathrm{Q} \mathrm{SAR})^{18}$ between neuroblocking activities and 1-(6-chloro-3-pyridyl- methyl)-2-nitroiminoimidazolidine analogues which is substituted at 5-position.

\section{Materials and Methods}

Molecular Modeling. The neuroblocking activities $(\log 1 /$ $\mathrm{BC})$ of $1-(5-(\mathrm{X})$ substituted-6-chloro-3-pyridylmethyl)-2nitroiminoimdazolidine analogues (1-21) as agonist at the

Table 1. Observed neuroblocking activities, Obs. $\log (1 / \mathrm{BC})$ of imidacloprid analogues and predicted activitics by $3 D-Q S \wedge R$ models

\begin{tabular}{|c|c|c|c|c|c|c|}
\hline \multirow{2}{*}{ No. } & \multirow{2}{*}{ Sub. (X) } & \multirow{2}{*}{ Obs. } & \multicolumn{2}{|c|}{ CoMFA } & \multicolumn{2}{|c|}{ COMSIA } \\
\hline & & & Pred. & Dev. & Pred. & Dev. \\
\hline 2 & $\mathrm{~F}$ & 5.99 & 5.94 & 0.05 & 5.68 & 0.31 \\
\hline 3 & $\mathrm{Cl}$ & 5.61 & 5.52 & 0.09 & 5.61 & 0.00 \\
\hline 4 & $\mathrm{Br}$ & 5.51 & 5.50 & 0.01 & 5.58 & -0.07 \\
\hline 5 & $\mathrm{I}$ & 5.30 & 5.31 & -0.01 & 5.54 & -0.24 \\
\hline 6 & $\mathrm{CH}_{3} \mathrm{O}$ & 4.98 & 4.50 & 0.48 & 5.04 & -0.06 \\
\hline 7 & $\mathrm{C}_{2} \mathrm{H}_{5} \mathrm{O}$ & 4.66 & 4.54 & 0.12 & 4.73 & -0.07 \\
\hline 9 & $i-\mathrm{C}_{3} \mathrm{H}_{7} \mathrm{O}$ & 4.46 & 4.40 & 0.06 & 4.53 & -0.07 \\
\hline 11 & $n-\mathrm{C}_{5} \mathrm{H}_{11} \mathrm{O}$ & 3.59 & 3.63 & -0.04 & 3.54 & 0.05 \\
\hline 12 & $\mathrm{CH}_{3}$ & 5.25 & 5.43 & -0.18 & 5.12 & 0.13 \\
\hline 14 & $n-\mathrm{C}_{3} \mathrm{H}_{7}$ & 4.51 & 4.50 & 0.01 & 4.41 & 0.10 \\
\hline 15 & $n-\mathrm{C}_{4} \mathrm{H}_{9}$ & 3.79 & 3.77 & 0.02 & 3.94 & -0.15 \\
\hline 16 & $\mathrm{C}_{6} \mathrm{H}_{3}$ & 4.46 & 4.56 & -0.10 & 4.33 & 0.13 \\
\hline 17 & $\mathrm{CF}_{3}$ & 4.43 & 4.38 & 0.05 & 4.54 & -0.11 \\
\hline 18 & $\mathrm{CO}_{2} \mathrm{CH}_{3}$ & 3.92 & 3.92 & 0.00 & 3.87 & 0.05 \\
\hline 19 & $\mathrm{CN}$ & 4.59 & 4.71 & -0.12 & 4.50 & 0.09 \\
\hline \multirow[t]{3}{*}{21} & $\mathrm{~N}_{3}$ & 4.98 & 4.99 & -0.01 & 5.07 & -0.09 \\
\hline & ARTS & & & 0.08 & & 0.11 \\
\hline & PRESS & & & 0.32 & & 0.27 \\
\hline
\end{tabular}

Pred.; predicted values by the optimized CoMTA model (A5) in Table 2 and COMSIA model (A3) in Table 3, Dev.; different between observed and predicted value, ARTS; average residual of training set, PRESS; redictive residual sum of squares of the training set. 
<smiles>[X]c1cc(CN2CCN/C2=N\[N+](=O)[O-])cnc1Cl</smiles>

Figure 1. General structure of $1-(6-c h l o r o-3-p y r i d y / m e t h y l)-2-$ nitroiminoimdazolidine analogues (1-21).

nicotinic acelylcholine receptor (nAChR) were taken from the litcrature ${ }^{15}$ and their activities are listed in Table 1. And Figure 1 represents the general structure of imidacloprid analogues cmployed in this study. Molecular ficld calculations and partial least-squares (PISS) analyses have been perfomed using the CoMTA and CoMSTA modules within SYTYY package (Version 7.1). ${ }^{20}$ The structures of imidacloprid analogues were energy-minimized using the SYBYI, energy minimizer (Tripos Forec Field) with a $0.01 \mathrm{kcal} / \mathrm{mol}$ energy gradient convergence criterion and Gästeiger-Hückel charge. ${ }^{-1}$ The lowest energy conformation was searched with simulated annealing method. ${ }^{22}$ Both CoMTA and CoMSIA models were obtained with 16 molecules in training set and 5 molecules in test set. The compounds of training set were aligned in 3 dimensional space by atom based fit $(A)^{23}$ and field fit $(\mathrm{F})^{2 \cdot 1}$ with alignment rule. For an example, one of the two alignments for training set, the atom based fit, is shown in Figure 2. And the CoMTA combined with hydrophobic interaction (HINT) analysis ${ }^{75}$ were carried out using the QSAR module of SYTBYI package.

Region Focusing. This is usually applied to culhance the predictability of a CoMFA and CoMSIA study. Region focusing is the weight application to the latice points within a COMFA and COMSIA region to enhanee or altenuate the contribution of those points for subsequent analysis. ${ }^{20}$ SiDev* Coeflicient values were used as weights, and among different weighting factors were applied in that 0.5 was found as most appropriate. To improve the predictability of the CoMFA and CoMSIA models, region focusing was attempted. According to the reference, ${ }^{26}$ a model improvement should only be trusted if the $\mathrm{q}^{2}$ value increases as much as $10 \%$.

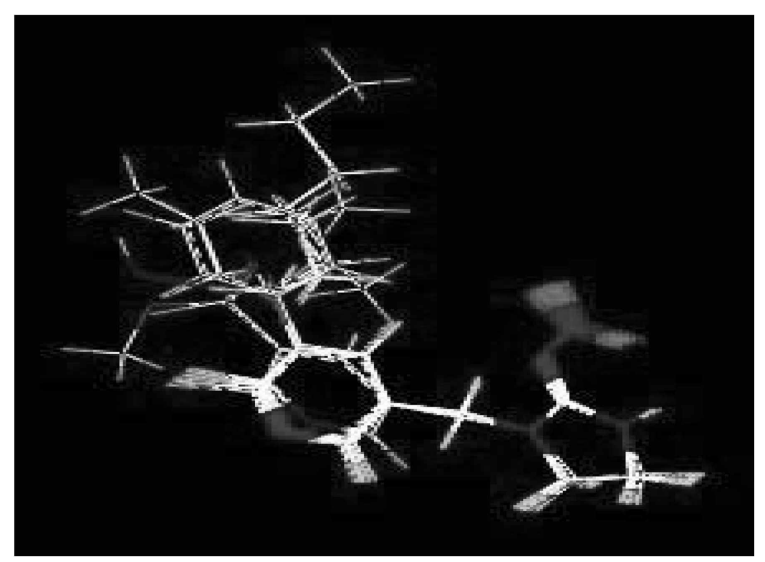

Figure 2. Alignment of the potential energy minimized agonists according 10 a least-squares atom based lit.
Partial Least Square (PLS) Analysis. This method was used to linearly correlate the activities with the CoMFA and CoMSIA values. To avoid over-fitted 3L-QSAR, the optimum number of components used in the model derivation is chosen from the analysis with the highest cross-validated correlation coefficient, $\mathrm{r}_{\mathrm{a}}^{2}$, (or $\left.\mathrm{q}^{2}\right)$. 3D-QSAR method can avoid some inherent deficiencies arising from the functional form of I cennard-Jones and Coulomb potentials. Moreover, the contour maps of the relative spatial contributions in the different fields can be substantially improved, which is very intuitive for interpretation in terms of separate property fields. ${ }^{77}$ The cross-validated $\mathrm{q}^{2}$ quantifies the prediclive ability of the model. It was determined by a leave-one-out (LOO) procedure of cross-validation in which one compound is removed from the datasel and its aclivity is predicted using the model derived from the rest of the data set. After the predictive quality of the best correlation model is determined, the optimum number of component is employed to do no validation PIS analysis in order to get the final model parameters such as correlation coefficient $\left(r^{2}\right)$, standard error of estimate (SFT) and $\Gamma$ value.

Calculation of 3D-QSAR Descriptors. COMTA and CoMSIA were performed with the QSAR option of SYBYL. ${ }^{20}$ For all steps of conventional CoMFA, the default SYTYYI. settings were used. The steric (S) and electrostatic (C) field energies were calculated using the Lennard-Jones potential and Coulomb potential $\left(\mathrm{sp}^{3}\right.$ carbon probe atoms with +1 charge). Also, potential atomic charges were calculated using Gasteiger-Hückel method. CoMFA grid spacing used in this work was $1,0-3.0 \mathrm{~A}$ in all $\mathrm{X}, \mathrm{Y}$ and 7 . directions. In addition to the fields used in CoMFA melnod, the CoMSIA method provides hydrophobic $(\mathrm{H}), \mathrm{H}$-bond donor (D) and H-bond acceptor (A) ficlds. ${ }^{2 k}$ Grid spacing used in this work was $1,0-3.0 \AA$ which is same as shown in CoMTA study. A probe atom with radius $1.0 \AA$, hydrophobicity of +1.0 charge and $\mathrm{H}$-bond properties (donor and aceeptor) of +1.0 was used to calculate steric, electrostatic, hydrophobic, and $\mathrm{H}$-bond fields, respectively.

\section{Results and Discussion}

Activities and Predictivity of the Models. The observed neuroblocking activity $(O b, \log (1 / \mathrm{BC}))$ of imidacloprid analogues (1-21) along with predicted activity (Pred.log.(1/ $\mathrm{BC})$ ) by CoMFA (A5) and CoMSIA models (A3), and the deviation (Dev.) of the predicted values from the observed values are summarized in Table 1 . The neuroblocking activities of halogen substituents (2-5) were higher than those for compounds having any other group at the corresponding 5position on pyridine ring. When the alkyl and alkoxy substituents with steric bulky groups were introduced as Xsubstituents, they showed little activities.

The results of CoMFA and CoMSIA analyses were summarized in Tables 2 and 3, respectively. The quality of the funal optimized CoMFA and CoMSIA model is measured by two statistical parameters, $\mathrm{r}^{2} \mathrm{nis}$ and $\mathrm{q}^{2}$ (or $\mathrm{r}^{2}{ }_{\mathrm{a}}$ ). The value of $\mathrm{q}^{2}$, which indicates the quantified predictability of 
Table 2. The summary of statistical results of CoMFA models" with two alignment types and field contribution (\%)

\begin{tabular}{|c|c|c|c|c|c|c|c|c|c|c|}
\hline \multirow{2}{*}{$\begin{array}{l}\text { Alignments } \\
\text { Models No. }\end{array}$} & \multicolumn{5}{|c|}{ Atom based fit } & \multicolumn{5}{|c|}{ Field fit } \\
\hline & Al & $\mathrm{A} 2$ & $\mathrm{~A} 3$ & A4 & $\mathrm{A}^{2}$ & F1 & $\mathrm{F} 2$ & $\mathrm{F3}$ & $\mathrm{F} 4$ & F5 \\
\hline Fields combination & s & I & SI & $\mathrm{SH}$ & SIH & s & $\mathrm{I}$ & SI & $\mathrm{SH}$ & $\mathrm{SIH}$ \\
\hline Grid $(A)$ & 2.5 & 1.5 & 2.5 & 2.5 & 2.5 & 2.5 & 1.0 & 1.0 & 1.0 & 1.0 \\
\hline Component & 4 & 4 & 4 & 4 & 4 & 3 & 4 & 3 & 3 & 3 \\
\hline$r_{m}^{2}{ }^{\prime}$ & 0.668 & 0.557 & 0.703 & 0.694 & 0.707 & 0.637 & 0.545 & 0.640 & 0.600 & 0.666 \\
\hline$r^{2} w^{2}=$ & 0.984 & 0.986 & 0.963 & 0.986 & 0.986 & 0.863 & 0.963 & 0.903 & 0.906 & 0.958 \\
\hline $\mathrm{SEE}^{d t}$ & 0.101 & 0.095 & 0.152 & 0.093 & 0.092 & 0.279 & 0.153 & 0.235 & 0.231 & 0.155 \\
\hline F-value & 165.844 & 187.785 & 71.640 & 194.962 & 200.631 & 25.253 & 70.659 & 37.176 & 38.659 & 90.562 \\
\hline Steric & 56.1 & 91.0 & 66.3 & 67.6 & 76.4 & 53.1 & 93.1 & 57.5 & 47.5 & 61.3 \\
\hline Electrostatic & 40.5 & 0.0 & 36.0 & 27.4 & 21.9 & 40.1 & 4.4 & 41.8 & 37.2 & 33.6 \\
\hline Hydrophobicity & 3.3 & 9.0 & 3.7 & 4.9 & 1.7 & 6.8 & 2.5 & 0.7 & 15.3 & 5.1 \\
\hline
\end{tabular}

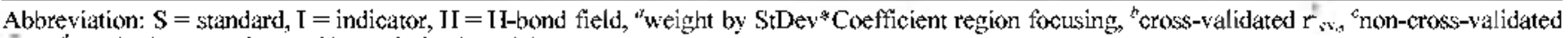
$\mathrm{r}_{\text {mev }}$, standard etror estimate, "the optimized model.

Table 3. The summary of statistical results of CoMSIN models" with two alignment types and ficld contribution (\%)

\begin{tabular}{|c|c|c|c|c|c|c|c|c|c|c|}
\hline \multirow{2}{*}{$\begin{array}{l}\text { Alignments } \\
\text { Models No. }\end{array}$} & \multicolumn{5}{|c|}{ Atom based fit } & \multicolumn{5}{|c|}{ Field fit } \\
\hline & A1 & $\mathrm{A} 2$ & $\mathrm{~A} 3^{\circ}$ & A4 & A5 & F1 & $\mathrm{F} 2$ & $\mathrm{~F} 3$ & $\mathrm{~F} 4$ & F5 \\
\hline Fields combination & SD & $\mathrm{SA}$ & SDA & SEAD & SHDA & SD & SHA & $\mathrm{SDA}$ & SEAD & SHDA \\
\hline Girid $(\hat{A})$ & 1.0 & 1.5 & 1.5 & 1.5 & 3.0 & 1.0 & 3.0 & 2.5 & 1.5 & 3.0 \\
\hline Component & 4 & 2 & 4 & 3 & 2 & 3 & 2 & 2 & 3 & 2 \\
\hline$r$ & 0.779 & 0.763 & 0.715 & 0.603 & 0.650 & 0.751 & 0.685 & 0.750 & 0.638 & 0.696 \\
\hline$r_{\text {wivec }}{ }^{c}$ & 0.904 & 0.906 & 0.961 & 0.881 & 0.899 & 0.901 & 0.845 & 0.854 & 0.887 & 0.851 \\
\hline $\mathrm{SEE}^{d t}$ & 0.244 & 0.222 & 0.157 & 0.260 & 0.231 & 0.237 & 0.285 & 0.277 & 0.254 & 0.280 \\
\hline F-value & 25.883 & 62.678 & 66.926 & 29.614 & 57.568 & 36.404 & 35.568 & 38.807 & 31.298 & 37.160 \\
\hline Steric & 94.6 & 67.8 & 68.2 & 54.8 & 52.2 & 82.5 & 45.1 & 61.3 & 54.8 & 44.1 \\
\hline Electrostatic & - & - & - & 30.2 & - & - & - & - & 22.3 & - \\
\hline Hydrophobicity & - & - & - & - & 27.8 & - & 38.4 & - & - & 37.6 \\
\hline H-bond Donor & 5.4 & - & 0.8 & 0.5 & 0.7 & 17.5 & - & 5.2 & 2.6 & 4.3 \\
\hline H-bond Acceptor & - & 32.2 & 31.0 & 14.5 & 19.4 & - & 16.5 & 33.4 & 20.3 & 14.0 \\
\hline
\end{tabular}

Abbreviation: $\mathrm{S}=$ steric, $\mathrm{E}=$ electrostatic, II = IIydrophobicity, $\mathrm{D}=\mathrm{II}$-bond donor, $\mathrm{A}=\mathrm{I}$ I-bond, acceptor, "weight by StDev ${ }^{*} \mathrm{Coefficient}$ region focusing, "cross-validated $r^{2}$; " "non-cross-validated $r_{n \text { cwo }}$ "standard error estimate, "the optimized nodel $(\alpha=0.3)$.

the model, should be greater than 0.50 and the value of $\mathrm{r}^{2}$ nov, which shows the self consistency of the model, should be greater than 0.90. And PRESS is the prediction error sum of squares. From the Table I, it was found that the two models showed good prediction for the neuroblocking activities because of low average residual (CoMFA: 0.08, CoMSIA: 0.11 ) and PRESS (CoMFA: 0.32 \& CoMSIA; 0.27) of training set, indicating good predictivity of the model. The $\mathrm{r}_{\mathrm{cv}}$ (or $\mathrm{q}^{2}$ ) values of the two optmized models were 0.707 and 0.715 , respectively. For further validation of the predictive power of the two models, observed $(O b s \cdot \log (1 / \mathrm{BC}))$ and predicted activities (Pred. $\log (1 / \mathrm{BC})$ ) of five compounds in the test set are shown in Table 4 . The two optimized models (CoMFA A5 \& CoMSIA A3) can suggest good prediction for neuroblocking activities of the test set. The average values of deviation by the two models were 0.09 and 0.12 , respectively.

Comparison of Predicted and Experimental. Predicted and experimental activities are shown in Table 1. To evaluate the CoMFA model as an example, a plot between observed activities and predicted activities of the training set molecules showed good linearity (Pred. $\log (1 / \mathrm{BC})=0.972$ Obs. $\log (1 / \mathrm{BC})+0.104, \mathrm{n}=16, \mathrm{~s}=0.147, \mathrm{~F}=297.554, \mathrm{r}^{2}=$ $0.955 \& \mathrm{q}^{2}=0.940$ ) as depicted Figure 3. Additionally, predicted versus experimental activities for the test set are shown within the correlation plot of the CoMFA analysis for the neuroblocking activity. As indicated in CoMFA, a CoMSIA plots between observed activities and predicted activities of the training set molecules show good linearity (Pred. $\log (1 / \mathrm{BC})=0.961$ Obs. $\log (1 / \mathrm{BC})+0.810, \mathrm{n}=16, \mathrm{~s}=$ $0.137, F=338.142, \mathrm{r}^{2}=0.960 \& \mathrm{q}^{2}=0.956$, not shown).

CoMFA Models for Activities. The statistical results of 10 CoMFA mode]s (AI-A5 \& FI-F5) with atom based fit and field fit alignment obtained from the combination of five fields (Standard, Indicator, Standard + Indicator, Standard + Hydrogen bond \& Standard + Indicator + Hydrogen bond) are listed in Table 2 . However, there are some important physicochemical parameters of insecticides whose hydrophobicity $\log P(0.00-5.50)$, dipole moment $(\mu=1.20$ - 10.20 debye), surface area (190-384 $\left.\AA^{2}\right)$, and molar refractivity $\left(\mathrm{MR}=48.0-121.0 \mathrm{Cm}^{3} / \mathrm{mol}\right)$, respectively, which are known to be taken up through the recent our study. ${ }^{29}$ Particularly, to 


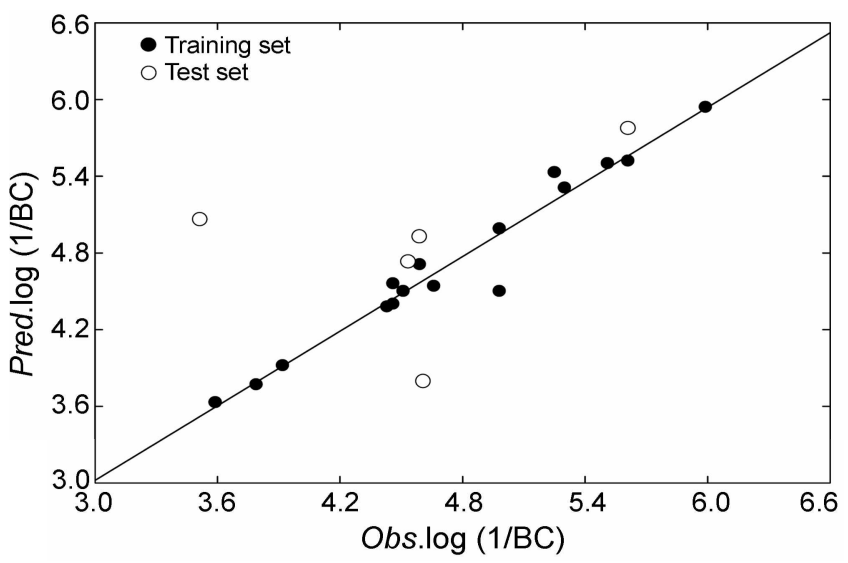

Figure 3. Relationships between observed neuroblocking activities, $O b s \cdot \log (1 / 13 C)$ and predicled neuroblocking activities, Pred $\log (1 /$ $B C$ ) by CoMF $\Lambda$ model $\Lambda 5$. (For training set; Pred log $(1 / \mathrm{BC})-$ $0.9720 b s \cdot \log (1 / \mathrm{BC})+0.104, \mathrm{n}-16, \mathrm{~s}-0.147, \mathrm{~F}-297.554, \mathrm{r}^{2}-$ $0.955 \& q^{3}=0.940$

account for the hydrophobic propertics, ClogP hydrophobicity (HINT) terms of molecules was included in the analysis as additional descriptor. ${ }^{23}$ Inclusion of these descriptors improved the statistical significance of the model. These descriptors may influence this type of activity, an important parameter to explain relationship between substrates and receptor. The optimized A5 model shows that leave-one-out cross-validated value $\left(\mathrm{r}_{\mathrm{c}}^{2}\right.$, or $\left.\mathrm{q}^{2}\right)$ is 0.707 and non crossvalidated conventional value $\left(r_{\text {nci. }}^{2}\right.$ ) is 0.986 , which can suggest good prediction for neuroblocking activitics of the training set. The contribution of steric, electrostatic and hydrophobic field was $76.4 \%, 21.9 \%$ and $1.7 \%$, respeclively. It suggests that steric bulk and electropositive nature of a compound is essential for high activity.

CoMSIA Models for Aetivities. The CoMSIA analysis with the same training set was performed. The statistical results of CoMSTA models (A1-A5 \& F1-F5) with atom based fit and field fit alignment obtained from the combination of five fields (Steric. Electrostatic, Hydrophobicity, $\mathrm{H}$-bond donor \& H-bond acceptor) and the 10 models are listed in Table 3. It was found that CoMSIA A3 model gave best results $\left(\mathrm{q}^{2}=0.715\right.$ and $\mathrm{r}^{2}$ ne: $\left.=0.961\right)$. The contribution of steric, $\mathrm{H}$-bond donor and $\mathrm{H}$-bond acceptor fields was $68.2 \%, 0.8 \%$ and $31.0 \%$, respectively. Therefore, this suggests that bulk and $\mathrm{H}$-bond acceptor nature of a compound may offer favorable steric interactions at the active site from the contour maps with the two models. In order to determine an appropriate attenuation factor $(\alpha)$, a Gäussian-type distance dependence function is applied. In preliminary parameter study, it was calibrated within the range from 0.1 to 0.9 , and $\mathrm{q}^{2}$ values were computed each time. Figure 4 represents the most proper attemuation factor, $\alpha$ value that is distance dependent between probe atoms and atoms in the molecule in CoMSIA model. From the relationships between $q^{2}$ and $\alpha$ values, our systematic parameter study on attenuation factor shows that $\alpha=0.3$ is optimum for these data sets. From the results of $3 \mathrm{D}-\mathrm{QSAR}$ analyses, the CoMFA and CoMSIA models from the atom based fit align-

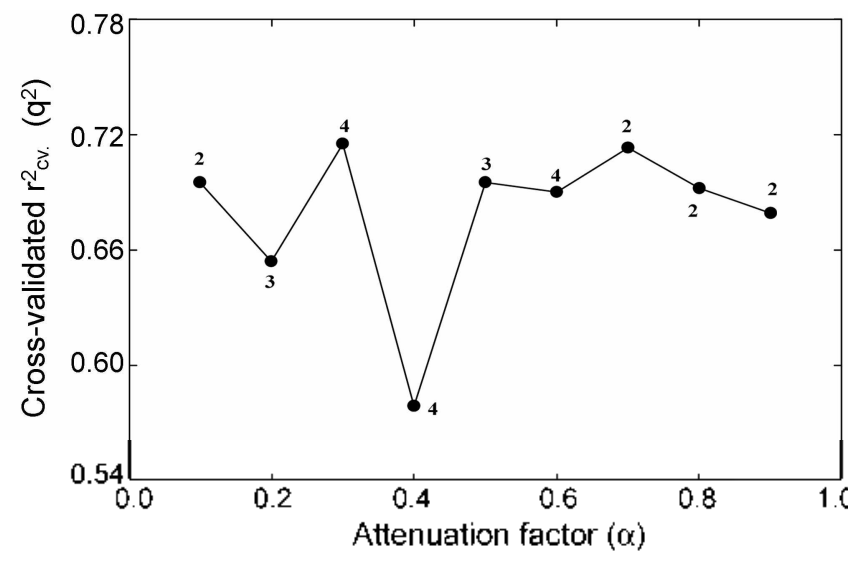

Figure 4. Variation of $r_{c^{2}}{ }^{2}$ (or $q^{2}$ ) upon changing the attentiation factor, a used in the distance dependence between the probe atom and the atoms of the molecules in CoMSIA A3 model.

ment (A) were better than that from the field fit alignment (F).

Contour plots of CoMFA and CoMSIA. The results of CoMTA and COMSTA analyses were graphically interpreted by field contour plots and the coefficient contour maps usine the field type 'StDev*Coefl' were generated as Figures 5 and 6 , respectively. At first, Figure 5 shows a contour plots with the optimized CoMFA model A5. In the steric and electrostatic contour plot (shown in left), there is a large green and blue contour at X-substituent. The plots indicate that both the steric and electrostatic regions mainly are in the vicinity of the $X$-substituent. Green color denoles the contribution to steric and blue color denotes the contribution to positive charge. A positive electrostatic potential region, favorable to aclivity, and overlaps the steric region around the X-substituent. According to 2D-QSAR study of the Xsubstituents at 5-position on the pyridine ring, the greater the electron-releasing resonance effect (-R), higher the activity. However, introduction of sizable and alkoxy substituents were unfavorable. "HINT contour plot (right) also shows cyan contour at the same site. Cyan color denotes the contribution to the hydrophilicity. It means that introducing steric bulky, positive charge and hydrophilic substituent as

Table 4. Observed neuroblocking activities, Obs, $\log (1 / 3 C)$ and predicted activities of imidacloprid analogues in the test set using 3D-QSAR models

\begin{tabular}{|c|c|c|c|c|c|c|}
\hline \multirow{2}{*}{ No. } & \multirow{2}{*}{ Sub. (X) } & \multirow{2}{*}{ Obs. } & \multicolumn{2}{|c|}{ COMFA } & \multicolumn{2}{|c|}{ COMSIA } \\
\hline & & & Pred. & Dev. & Pred. & Dev. \\
\hline 1 & $\mathrm{H}$ & 5.70 & 5.50 & 0.20 & 5.79 & -0.09 \\
\hline 8 & $n-\mathrm{C}_{3} \mathrm{H}_{7} \mathrm{O}$ & 4.56 & 4.58 & -0.02 & 4.65 & -0.09 \\
\hline 10 & $n-\mathrm{C}_{.} \mathrm{H}_{2} \mathrm{O}$ & 4.58 & 3.66 & 0.92 & 3.83 & 0.75 \\
\hline 13 & $\mathrm{C}_{2} \mathrm{H}_{5}$ & 4.66 & 4.88 & -0.22 & 4.85 & -0.19 \\
\hline \multirow[t]{2}{*}{20} & $\mathrm{NO}_{2}$ & 3.60 & 5.05 & -1.45 & 4.42 & -0.82 \\
\hline & ARTS & & & 0.09 & & 0.12 \\
\hline
\end{tabular}

Pred: predieted values by the oplimized CoMFA model ( $A 5)$ in lable 2 and CoMSI $\Lambda$ model $(A 3)$ in Table 3, Dev; different between observed and predicted value, $\Lambda \mathrm{RTS}$; ilverage residual of test set. 

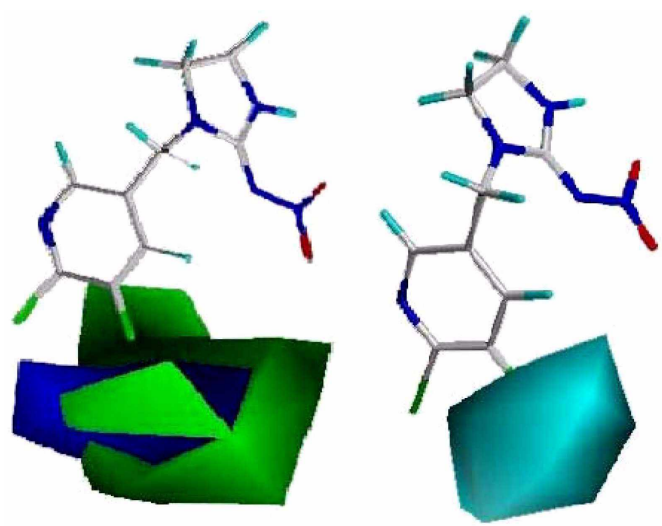

Figure 5. The contour plot of the CoMFA for the neuroblocking activities. lelt: the steric and electrostatic fields \& right: CoMFAIIIN'T contour plot for hydrophilic field (sidev*coefi). The most active compound (2) is shown in capped sticks. (contour levels: favor; $80 \%$ \& disfavor; $20 \%$.
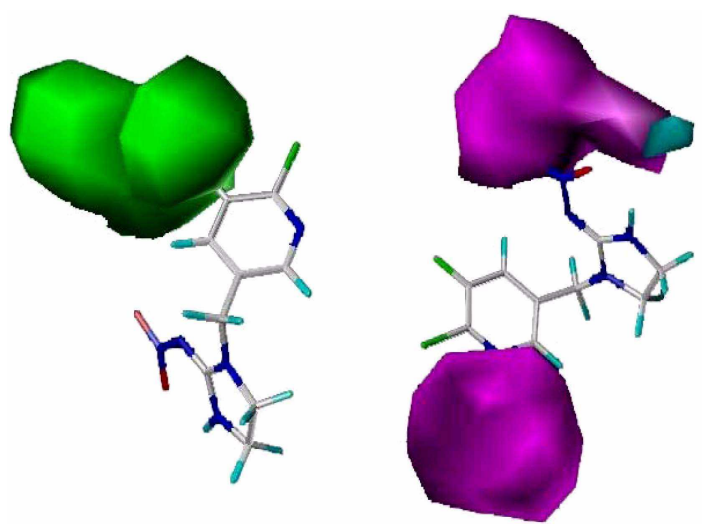

Figure 6. The contour plot of the CoMSlA for the neuroblocking activities. Right: for the sierie field \& Left: HI-bond donor and IIbond acceptor fields (stdev*coeff), the most active compound ( 2 ) is shown in capped sticks. (contour levels: favor; $80 \%$ \& disfavor; $20 \%$ ).

$\mathrm{X}$-substituent improves the neuroblocking activities.

The contour plots with optimized CoMSIA model (A3) are illustrated in Figure 6. Green color denotes the contribution to the steric field and magenta color denotes the contribution to H-bond acceptor. CoMSIA steric contour plots (left) show similar tendency to that of CoMFA. ${ }^{13 \mathrm{C}} \mathrm{H}$ bond donor and acceptor contour plot (right) shows that $\mathrm{H}$ bond acceptor region (magenta), favorable to activity, located at nitrogen atom on the pyridine ring and nitro group on the imidazolidine ring. But $\mathrm{H}$-bond donor $^{301}$ favor region (cyan) located at one of the oxygen atom on nitro group. Based on these findings, the 3D-QSARs between X-substituents of imidacloprid analogues and their neuroblocking activities may be useful for designing better neuroblocking insecticides development.

\section{Conclusion}

The 3D-QSAR studies were performed for neuroblocking of imidacloprid analogues using CoMFA and COMSIA methodology and highly predictive 3D-QSAR models were generated for neuroblocking for the treatment of imidacloprid analogues. The optimized CoMFA model (A5: $r_{\mathrm{c} .}=$ $\left.0.707 \& r_{\text {tik. }}^{2}=0.986\right)$ and CoMSIA model (A3: $r^{2}=0.715$ $\left.\& r_{\text {tis. }}^{2}=0.961\right)$ for neuroblocking activity cxhibited a good correlation. The contribution of steric, $\mathrm{H}$-bond donor and $\mathrm{H}-$ bond aceeptor ficlds was $68.2 \%, 0.8 \%$ and $31.0 \%$, respectively. The two models generated from the atom based fit alignment (A) were better than that from the field fit alignment (F). From the contour plots with the two models, introducing steric bulky, positive charge and hydrophilic group as $\mathrm{X}$-substituent improves the neuroblecking activities. And $\mathrm{H}$-bond acceptor region which is favorable to activity, located at nitrogen atom on the pyridine ring and nitro group on the imidazolidine ring. Therefore, the models indicate the significant correlation of steric and $\mathrm{H}$-bond acceptor ficlds with neuroblocking activities of imidacloprid analogues.

Acknowledgement. This work was supported by a grant (No. R11-2002-100-03005) from ГERC program of the Korea Science and Fngineering Foundation (KOSTF).

\section{References}

1. The British Crop Protection Council. In The Pesticide Manual, 13th ed.: The Royal Society of Chemistry; Tomlin, C. D. Ed.; Hampshire, UK. 2003; p 562 .

2. (a) I lollingworth, R. M. In Agrochentical Discerery, Insect. Weed. and Fungal Confrol: Baker, D. R., IImetsu, N. K., Eds.: ACS Symposium Series 774; Washington DC, 2001; p 238. (b) Kagabu, S. Rev. Toxicol. 1997, I, 75 .

3. Levin, E. D.; Simon, B. B. Psychophamacologe (Berlin) 1998, $138,217$.

4. Simms, I. C.; Fster, A.: Wilson, M. J. Crop, Protection 2006. 25, 549.

5. Byme, F. J.; Toscano, N. C. Crop. Protection 2006, 25, 831.

6. Capowiez, Y.; Berard, A. Ecotoxicol Eminon. Saf. 2006, 64, 198.

7. (a) Kim. H. J.: Shelver, W. L.; Li, Q. X. And. Chim. Acta 2004, 50\%, 111 . (b) Watanabe, E.: Eun. H.; Baba, K.; Arao. T.; Ishi, Y.; Findo, S.: Ueji, M. J. Agric: Ford Chem 2004, 52, 2756. (c) 7hang, N.; Tomizawa, M.; Casida, J. F. Netrosci. Lett. 2004, $37 /$. 56.

8. Guez, D.; Belzunces, L. P.: Maleška, R. Pharm. Biochen. Behav. $2003,75,217$

9. (a) Jepson, I. E. C.; Brown, L. A.; Sattle, D. B. Inver. Nerrosci. 2006. 6, 33. (b) Thara, M.; Brown, I. A.; Ishida, C.; Okuda, IJ.; Sattelle, D. B.; Matsuda, K. J. Pestic: Sci. 2006, 3, 35. (c) Kagabu. S.: Kato, C.; Nishimura, K. J. Pestic. Sci. 2004, 29, 376.

10. Decourtye, A.; Devillers, J.; Cluzeau, S.; Charreton, M.: Pham[Delegue, M. H. Ecotoxi. Environ. Saf, 2004, 57, 410.

11. Rancan, M.; Sabatini, A. G.; Achilli, G; Galletti, G. C. Anch. Chim. Acto 2006. 555, 20.

12. Karabay, N. U.A Oguz, M. G. Gen. Mot. Res. 2005, 4, 653.

13. (a) Matsuo, Il.; Tomiratwa, M.; Yamamolo, 1. Arch Insect Biochem. Physiol. 1998, 37, 17. (b) Yamamolo, l.; Jomicawa, M.; Saito, T.; Miyamoto, T.; Walcott, E. C.; Sumikawa, K. Arch. Insect. Bicchem. Plysiol. 1998, 37, 24. (c) Okazawa, A.; Akamatsu. M.; Ohaka, A.; Nishiwaki, Il.; Cho. W. J; Nakagawa, Y; Nishimura, K.; Jeno, T. Pestic. Sci. 1998, 54, 134. (d) Nishiwaki, Il.; Nakagawa, Y.: Takeda, D. Y.; Okarawa, A.: Akamatsu, M.: Miyagawa, H.; Ueno, T.: Nishimura, K. Pest. Mamag Sci. 2000, 56, 875. (e) Kagabu, S.; Ito, N.; Imaj, R.; Hieta, Y.: Nishimura, K. J. Pestic. Scti. 2005, 30, 409. 
14. Nicolotti, O.; Altomare, C.; Pellegrini-Calace, M.; Carotti, A. Curr. Topics Med. Chem. 2004, 4, 335.

15. Sung, N. D.; Yu, S. J.; Kang, M. S. Agri. Chent \& Biotechnol. $1997,40,53$.

16. (a) Cramer, R. D.; Palterson, D. E.; Bunce, J. D. J. Am. Chem. Soc. 1988, 110, 5959. (b) Cramer, R. D.; Bunce, J. D.; Patlerson, D. E. Quant. Sinct. Act. Relat. 1988, 7, 18.

17. (a) Klebe, G.; Abraham, U.; Mietzner, T. J. Med. Chem. 1994, 37 , 4130. (b) Kebe, G; Abraham, U. J. Coniput. Aided Mol. Des. $1999,13,1$.

18. Folkers, G; Merz, A.; Rognam, D. In 3D-QSAR in Ding Design: Theory; Methods and Applications; Kubinyi, H., Ed.; ESCOM Science Publishers, B. V.: 1993; p 583.

19. Nishimura, K.; Kiriyama, K.; Kagabu, S. J. Pesfic. Sci. 2006, 31, 110.

20. Syby/ Moleculor Modeling and QSAR Soffware on CD-Rom (Ver. 7.1), Theory Manual; Tripos Inc.: St. Louis, U.S.A., 2005.

21. Purcell, W. P.; Singer, J. A. J. Chem. Eng. Data 1967, 122, 235.

22. Kerr, R. Biophys. J. 1994, 67, 1501.
23. Marshall, G. R.; Barry, C. D.; Bosshard, H. E.; Dammkoehler, R. A.; Dunn, D. A. In Conputerassisted Drug Design: Olsen, E. C.; Christoffersen, R. E., Eds.; ACS: Washington D.C., 1979; p 205.

24. Clark, M.; Cramer III, R. D.; Jones, D. M.; Pallerson, D. E.; Simerroth, P. E. Tetrahedron Comptit. Methodol 1990, 3, 47.

25. Kellogg, Gi E.; Semus, S. F.; Abraham, D. J. J. Comp.-Aided Mol. Design 1991, $5,545$.

26. (a) Lindgren, F.; Geladi, P.; Rannar, S.; Wold, S. J. Chenonetrics 1994, 8, 349. (b) Lindgren, F.; Geladi, P.; Berglund, A.; Sjostrom, M.; Wold, S.; Chemometrics, J. J. Chemometrics 1995, $9,331$.

27. (a) Klebe, G. In 3D-QSAR Dng Design, Theory; Methods and Applications; Kubinyi, H., Ed.; ESCOM: Leiden, 1993; p 173. (b) Klebe, G; Abraham, U. J. Comput. Aid. Mol. Des. 1999, 13, 1.

28. Klebe, G.; Abraham, U.; Mietzner, T. J. Med. Chem. 1994, 37, 4130.

29. Sung, N. D.; Song S. S. J. Korean Soc, Agric, Chem. Biotechol. $2003,46,280$.

30. (a) Euter, M. C. Acc. Chem. Res. 1990, 23, 120. (b) Taylor, B.; Kennard, O. Acc. Chent. Res. 1984, 17, 320. 